\title{
Internal auditor reports a fraud: Courage and pressure
}

\author{
Dini Rosdini ${ }^{a}$, Aria Farah Mita ${ }^{b^{*}}$ and Dyah Setyaningrum ${ }^{b}$
}

${ }^{a}$ Faculty of Economics and Business, Universitas Padjadjaran, Indonesia ${ }^{b}$ Faculty of Economics and Business, Universitas Indonesia, Indonesia

\section{H R O N I C L E}

\begin{tabular}{l}
\hline Article history: \\
Received March 9, 2021 \\
Received in revised format May \\
112021 \\
Accepted May 312021 \\
Available online \\
May 312021 \\
\hline Keywords: \\
Audit findings \\
Courage \\
Pressure \\
Fraud \\
Internal auditor
\end{tabular}

\section{Introduction}

Internal audit is defined as an independent, objective assurance and consulting activity designed to add value and improve an organization's operations (Othman et al., 2015; Bartolucci et al., 2011). Its role incorporates activities such as detecting, preventing, and monitoring fraud risks and overcoming these risks in audits and investigations (IIA, 2019). Internal auditors play an essential role to assist the company in executing and achieving performance targets and to assist the company in improving its performance. The works of internal auditors are carried out using a systematic approach by evaluating and improving the effectiveness of internal control and provide feedback on deficiencies found during the evaluation in the form of audit findings. Fraud is any unlawful act indicated by deceptiveness, cover-up, or violation of trust (IIA, 2017). Internal auditors play an important role in fraud detection. Losses can be minimized or even anticipated when fraud is found early. Thus, the organization's control environment is managed by supporting the application of effective internal control procedures that can prevent fraud. The International Standards for the Professional Practice of Internal Auditing or IPPF (IIA, 2017) mentions several points related to the responsibilities of the internal auditor in detecting, preventing, and monitoring fraud risk and giving attention to this fraud risk in audits and investigations. As many as $63.8 \%$ of the Internal Auditor fraud cases were identified through internal audit activities (Hunt, 2014). Coram et al. (2008) found that organizations with an internal audit function are more likely to identify and report fraud (self-report fraud) than organizations that do not have an Internal Auditor function. Baker (2007) mentioned that companies believe that internal

* Corresponding author

E-mail address: aria.farahmita@ui.ac.id (A. F. Mita)

C 2021 Growing Science Ltd. All rights reserved. doi: $10.5267 /$ j.ac.2021.6.001 
auditors are liable for identifying fraud. When the internal auditors have discovered indications of fraud, consequently they should report the fraud to top management for further action. The behavioral aspect strongly influences the desire to report and the courage of the internal auditors to report fraud in decision making. The internal auditor's report is a means of communication which encompasses the main audit activities and critical findings prepared according to the reporting standards in the professional standards of the Internal Auditor (IIA, 2017). When the internal auditors find indications of fraud, the next step is to report the fraud in the audit report. The problem is the internal auditors may choose not to report the fraud. Several factors can influence the Internal Auditor's decision on whether to report or not to report indications of fraud. These include superior pressure, level of expertise, as well as their risk preferences and personality. Job pressure creates auditors' dilemma on whether they can maintain their honesty and professionalism.

Previous research has found that when internal auditors are in a situation of pressure, fear, and unpleasantness, it will interfere with their decision-making process to make decisions that are in line with the company's values and interests. They tend to choose actions that keep them safe. Their professional moral courage was interfered with so that they are not able to properly assess the impact of the fraud findings on the company (Everett \& Tremblay, 2014; Norman et al., 2010; Khelil et al., 2018). That previous research has not yet tested the internal auditors' courage in reporting indications of fraud. Research results have novelty value for the scientific world and internal audit practice. In addition, this study uses an experimental method which is the most appropriate method for testing behavior, in this case, the internal auditor's behavior. This research is important because the internal auditor's courage to report fraud is essential for the effectiveness of the company's internal control and the company's survival from the damage caused by fraud. Courage to action in reporting fraud is the right action in line with the company's long-term interests. Firstly, this study aims to examine whether internal auditors have the courage to report fraud findings when they are under high pressure and an unpleasant situation being feared to be relocated to a remote area. Secondly, this study wants to justify that the pressure from fear and the unpleasant situation will not influence the courage of the internal auditor to report findings other than fraud. This study uses an experiment with 107 participants who were internal auditors from various companies. Participants were divided randomly into two groups with different treatments. The first group was given the low-pressure treatment and the second group was given the high-pressure treatment. The hypotheses are tested using One-Way ANOVA. This study proves that there is no difference in the number of findings reported under low- or high-pressure conditions. This finding proves that there are no issues regarding the willingness and courage of auditors in reporting audit findings. Furthermore, the research results show that pressure influences auditors' courage to report fraud findings. Internal auditors with a low pressure are more willing to report indications of fraud than IA with high pressure. These results confirm Sekerka et al. (2009), who state that when auditors are faced with an ethical dilemma between professionalism and work pressure, the auditors choose safe actions for themselves. This research contribution is to provide empirical evidence that if under pressure, internal auditors will hide indications of fraud in general findings and do not report explicitly. Research using experiments used in this study can show that courage is one of the factors that influence auditors to report fraud. Fear and worry of being transferred to a more remote area of duty become a "punishment" which makes the auditors choose not to report fraud. Internal auditor courage has been studied only in general in the context of the working environment (Sekerka et al., 2009; Everett and Tremblay, 2014). Internal Auditor is a profession that demands high integrity and professionalism. Including findings and reporting indications of fraud in an audit report is very important and certainly requires courage from the IA. Therefore, this study focuses on the behavior of internal auditors, especially courage IA, in reporting the indications of fraud they find.

\section{Theory and hypothesis development}

When the internal auditors find indications of fraud, the next step is to include the fraud in the audit report and submit it to top management for further action. The desire and courage of internal auditors to report fraud can be explained by behavioral theory in decision making. The decision in question is whether the auditor includes fraud findings in the report or not. Edwards's (1961) Behavioral Decision Theory is described as a theory that studies the trade-offs a person faces when deciding. The model in decision-making is maximizing utility. The measurement process involves a subjective element in considering the probability of what will happen in the future. Examples of trade-offs faced by someone, such as someone who will start a business, will face a trade-off between probability of loss and the expected profit. In addition to the element of subjectivity, Edwards (1961) also explained that decision-making is also influenced by one's personality. In line with Edwards (1961), Natenzon (2011) states that decision-making behavior provides an overview of the probability of human action in general. Individuals often exhibit behavior in choosing an action that depends on the context of decision-making. The decision-making process uses the principle of maximizing utility in individual decision-making. Furthermore, Slovic et al. (1984) describe that the perception of a particular risk or hazard that is likely to be faced as an impact on a decision will affect one's decision making.

This research focuses on how the internal auditors' professional moral courage influences the decision to act to report fraud in an unpleasant situation where there is pressure from the top management. Professional moral courage is a managerial competence that internal auditors must possess. Sekerka et al. (2009) mention five dimensions of professional moral courage, namely moral agency, multiple values, endurance of threat, going beyond compliance, and moral goals. Decisionmaking to report fraud findings will depend on the extent to which individuals consider the risks and dangers of pressures 
and threats that arise from including fraud findings in the audit report. Thus, the situation of decision-making faced by internal auditors is "pressure". Thus, although internal audit professional and ethical standards guide internal auditors to play the role of truth-tellers in an organization, internal auditors still face ethical conflicts when disclosure of audit results can negatively impact earnings, position, or the survival of their companies or their careers. Khelil et al. (2016) emphasize the need for moral courage to face ethical dilemmas in carrying out the role of the internal auditor. Auditors who have moral courage will find ways to fight pressure and overcome fear to behave according to companies' values and ethics. In the context of decision making, choking under stress occurs when individuals make effective decisions in low-pressure situations and make less than optimal decisions when under stress. Thus, their decision-making performance decreases as the level of pressure increases. (Byrne, Silasi-Mansat, \& Worthy, 2015; Markman, Maddox, \& Worthy, 2006). Stress often occurs in situations where there is a risk of success or failure. As a result, these situations can bring out certain traits or characteristics, such as loss, narcissism, and fear of negative evaluations, which can significantly affect individual performance (Byrne et al., 2015). Furthermore, Byrne et al. (2015) stated that in the decision-making process at work, individuals under pressure are likely to reduce the use of available cognitive resources to make optimal decisions. Based on the above discussion, individuals such as internal auditors who are under pressure will not be able to make optimal decisions in accordance with the company's values and interests. The accounting literature recognizes and reflects the importance of evaluating the impact of pressures generated within the accounting organization on auditor attitudes, intentions, and behavior. Specifically, the extant literature provides evidence that auditors are susceptible to inappropriate social influence pressure from superiors (Lord \& DeZoort, 2001; Argyle, 1957). According to the IPPF Standard (IIA, 2017), internal auditors must have sufficient knowledge to evaluate the risk of fraud and how it is handled by the organization. As mentioned earlier, if an internal auditor is under pressure, he or she would be less likely to make an optimal decision. The pressure situation will impair their professional moral courage and interfere with their judgment in evaluating the risk of fraud. Hence, the auditor will be less likely to report fraud. Everett and Tremblay (2014), Norman et al. (2010) found that internal auditors are often hesitant to report the fraud. They are afraid of unpleasant consequences which may affect them both personally and professionally. This kind of pressure they are facing comes from within the organization. So, the first hypothesis in this study are as follows:

\section{$\mathrm{H}_{1}$ : Internal auditors in low-pressure conditions are more likely to report indications of fraud found in the audit process compared to internal auditors in high-pressure conditions.}

According to Byrne et al. (2015), the pressure will be more likely to reduce cognitive resources available to make an optimal decision to report the audit findings. This research will also examine whether pressures will have a pervasive effect on internal auditors in carrying out their roles so that it will interfere with their ability to report other audit findings besides fraud. This study will examine whether professional moral courage can still be carried out by internal auditors and still not interfere with their decisions in reporting audit findings other than fraud. Hence, the second hypothesis is as follows:

$\mathrm{H}_{2}$ : Internal auditors in low-pressure conditions are more likely to report audit findings compared to internal auditors in high-pressure conditions.

\section{Research method}

This research uses an experimental method. The experimental method is the most appropriate method to determine the causal relationship between the independent and dependent variables (Leary, 1995). Research on human behavior is more appropriate to use experimental methods to obtain better internal validity than survey methods (Evans, Hannan, Krishnan, \& Moser, 2001). Since the internal auditor's courage in reporting fraud is a behavior, it is appropriate to test it using an experimental method. The method we use will provide more accurate results, if we use the survey method, which can only test to the affective and cognitive levels. The main characteristic of the experiment is that the researcher has control over the independent variable, which will cause changes in the dependent variable. This research data is primary data. The data collection technique is to invite participants to be involved in a laboratory experiment. The number of internal auditors involved in this experiment is 117 people, but only 107 pass the manipulation check. Thus, the number of the participants are 107 internal auditors. The respondents have good competence in internal audit since most of them have CIA/QIA certification with 1-5 years of experience. This experiment aims to assess participants' willingness to report indications of fraud and assess the number of findings reported in the Audit Result Report. This experiment used the between-subjects approach, which was divided into two groups. The first group was the treatment group that was given the high-pressure scenario and the second group was the control group who received different treatment from the experimental group, namely the low-pressure scenario. Each experimental design is $1 \times 2$, between-subjects. The worksheets used to test the first and second dependent variables are the same. There is a background explanation in the worksheet that they are internal auditors at $\mathrm{ABC}$ Company with different supervisory conditions between Group 1 and Group 2 . Then in the worksheet, there are 4 audit findings, and 1 of them is a finding that indicates fraud where there is a sentence that top management received some funds from the vendor. Participants are asked to write down these findings in the Audit Result Report, which template has been provided by the experimenter. Researchers want to know whether participants will report all 4 items of audit findings or not and find out whether participants will write the words "fraud" or "fraud indication" in the audit report on the worksheet. The first independent variable (fraud reporting) is analyzed by looking for the word "fraud" in the Audit Report on the experimental worksheet. To analyze the second independent variable (audit findings), researchers count the number 
of findings reported by participants in the Audit Results Report. The treatment of high pressure and low pressure used the same basis of scenario, that is, participants are given information about the audit findings of ABC company during the audit period in the year concerned. The difference is some sentences show that the pressure from the top management is high or low. The High-Pressure scenario used the sentence "The company's top management is firm and very happy when all subordinates carry out their instructions and directions. There is a fact of experience at ABC company when one of the internal auditors reported their audit findings even though top management asked not to be published, then ended up being transferred to the company's branch in a remote area. " The Low-Pressure scenario used the sentence "The Company's top management has good integrity and is very open to every aspiration and upholds a clean and corruption-free organizational culture." Then, all participants in the "High Pressure" and "Low Pressure" groups were asked to report their audit findings and report indications of fraud.

\subsection{Randomization process}

The sample criteria in this study were internal auditors at several companies with at least 2 years of experience. Internal auditors who have these criteria are then invited to participate in the experiment. After all the participants entered the room, the researcher divided into two groups: Group 1 as the treatment group and Group 2 as the control group. The selection of participants into each group was carried out randomly by distributing worksheets with different scenarios to participants in each row of chairs in turn. Participants who received the worksheets with code "1" were entered into Group 1, while participants who received the code " 2 " were assigned to Group 2. This randomization process had met the criteria for randomizing samples.

\subsection{Validity Threat}

To fulfil internal validity, this study has been considered (1). Randomization. The aim is that each group or cell in this study contains people who are expected to have the same variation so that each group can be compared directly; (2) History Deterrence. History is certain events experienced by the subject during the experiment which are not manipulation of the experiment but can affect the reaction of the subject. To prevent this historical occurrence, the experiment was conducted at 9 am so that participants have not been exposed to information and other thoughts from activities before doing the experiment; (3) Maturation Deterrence. Maturation is a natural change that a subject experience due to the passage of time. To avoid maturation, the experiment is conducted in 45 minutes duration; and (4). Mortality Deterrence. Mortality is the failure of the subjects to continue participating in the experimental process, possibly because they are too tired or bored, so that they decide to stop their participation (Rosdini et al., 2020). The participant was required to follow the experiment procedure from the beginning until the end, and it is prohibited to take a bathroom break or take a phone call.

\section{Results and discussion}

As mentioned above, the experiment was carried out on 107 participants who were internal auditors from various companies. Participants were divided randomly into two groups with different treatments. The first group was given the "low pressure" treatment in the form of information that "the top management of the company has good integrity and is open to every aspiration. In addition, management also upholds an organizational culture that is "clean and free of corruption". Meanwhile, the second group was given "high pressure" treatment in the form of information that "the Company's top management is firm and happy when all subordinates carry out their instructions and directions. There is a fact of experience at ABC company when an internal auditor reports the requested audit findings not to be included in the Audit Report by top management and ends with the relocation of the auditor from the internal audit unit to the company / working unit in a remote area. Participants in all groups were provided with information on 4 points of audit findings, one of which is an indication of fraud found by the internal auditor. Participants are then asked to fill/write the audit findings in the blank space of the Audit Findings Report section provided by the researcher. The internal auditor's courage in reporting fraud can be measured from the inclusion of the fraud finding in the audit finding report section. The results of hypothesis 1 that examine whether the Internal Auditors with low pressure will be more courageous in reporting fraud indications in the audit process than Internal Auditors with high pressure can be seen in the following Table 1.

Table 1

The Average of Fraud Reporting

\begin{tabular}{ccccc}
\hline & $\mathrm{N}$ & Mean & Std. Deviation & Difference Significancy \\
\hline Low Pressure & 52 & 0.7308 & 0.44789 & 0.0000 \\
High Pressure & 55 & 0.2000 & 0.40369 & \\
\hline Total & 107 & 0.4579 & 0.50057 & \\
\hline
\end{tabular}

This study uses One-Way ANOVA. Based on the mean difference test, it appears that reported fraud cases are higher when management imposes lower pressure on the work environment. From Table 1 on average, those that include fraud findings in the audit results report are mostly reported by internal auditors who receive low pressure from top management than internal auditors who receive high pressure. This mean difference is significant at $\alpha=1 \%$. The results of the study confirm 
the research of Byrne et al. (2015) stated that in decision-making situations, individuals who are under pressure will be more likely to reduce the use of available cognitive resources to make optimal decisions. Further, this result is consistent with Everett and Tremblay (2014), Norman et al. (2010), that internal auditors frequently remain silent out of fear of unpleasant consequences to their personal and professional results from organizational pressures. In the treatment of groups that get low pressure from top management, it is also explained about the company's culture that the top management has good integrity, committed to clean management, and free of fraud. The top management is very open to every aspiration. This may indicate that this situation will increase internal auditors' moral courage when they find fraud. They have the willingness and courage to report the fraud findings. This indication is in accordance with the research by Byrne et al. (2015). The results of the second hypothesis, which examine that the internal auditors with low pressure will report more audit findings than internal auditors with high pressure, can be seen in Table 2.

Table 2

The Average of Numbers of Reported Audit Findings

\begin{tabular}{ccccc}
\hline & $\mathrm{N}$ & Mean & Std. Deviation & \\
\hline Low Pressure & 52 & 3.0192 & 1.421 & Difference Significancy \\
High Pressure & 55 & 3.0545 & 1.45829 & 0.899 \\
\hline Total & 107 & 3.0374 & 1.43359 & \\
\hline
\end{tabular}

From Table 2, the pressure on the internal auditors has no effect on the number of findings reported. Even from the sample of this study, internal auditors who received high pressure reported more findings than those who received low pressure. This shows that no matter how much pressure is faced by internal audit, it will not change the number of findings reported because internal auditors view that reporting findings are an obligation and an indicator of their performance as internal auditors.

The results of this study indicate that pressure does not have a broad impact, it is limited to the decision of internal auditors to report fraud findings but is not shown in the auditor's decision to report findings other than fraud. This result is inconsistent with Byrne et al. (2015) 's research, stating that the pressure situation will not always reduce the cognitive resources of auditors in making decisions. These results imply that pressure is only relevant in certain situations when internal auditors detect fraud findings. Internal auditors' perceptions of the impact of fraud will further endanger the company so that the organization's situation becomes even more severe when fraud is found. Pressure from top management regarding the risk and threat of being relocated to a remote work location has a different effect on reporting fraud findings and reporting other audit findings besides fraud. This is consistent with Slovic et al. (1984) that in the decision-making process to report the findings in the audit report will depend on the individual's perception of the risks and hazards they will face because of the decisions to report the fraud findings.

\section{Conclusion}

The internal auditor plays an important role in detecting, preventing, and monitoring fraud risk in audits and investigations. After fraud indications are found, the internal auditor must report the fraud to top management for further action. Many behavioral aspects affect the internal auditor's decision to report fraud indication. One of them is courage. The purpose of this study is to examine that when facing high-pressure condition, do internal auditors have the courage to report fraud? Given the same condition, is the result different if the findings are non-fraud cases?

To answer the research question, this study uses experiment. The experiment in this study consisted of 2 series of experiments. Each of these experiments used a between-subjects approach, which was divided into two groups. The first group was the experimental group, which was given the high-pressure scenario. The second group was the control group who received different treatment from the experimental group, namely the low-pressure scenario. The experimental design is $1 \times 2$. The experiment was carried out on 107 participants who were internal auditors from various companies consisting of the private and public sector.

The result shows that the Internal Auditors with low pressure will be more courageous in reporting fraud indications in the audit process than Internal Auditors with high pressure. This result consistent with previous research mentioning that unpleasant and professional consequences made internal audit choose to remain silent. Moreover, when the finding is nonfraud cases, there is no difference in the number of frauds reported in low- or high-pressure conditions. This result confirms that reporting findings (non-fraud) is an internal auditor's main task.

This research implies that the courage of the internal auditor to report fraud is essential for the effectiveness of the company's internal control and the company's survival from the damage caused by fraud. Courage to action in reporting fraud is the right action in line with the company's long-term interests. Further study can incorporate other behavioral aspects such as competence, risk preferences, and internal auditor personality to see a comprehensive picture of all behavioral aspects that affect decision making in reporting fraud. Besides, this research implies for internal audit practices in planning Top Management to be more open, one way by creating an open organizational culture (creating a collegial and conducive work environment), then enlisting shareholders to provide Key Performance indicators (KPIs) of openness and closeness 
of top mgt with employees. (How often do top management hold town hall meetings with employees in a year, for example, or is there any media for employees to convey aspirations to top management). The results of this research can be interpreted by considering the limitation of the research. This research did not yet include covariate variables. Further Research can add covariate variables, for example, the internal competence of auditors.

\section{Funding Statement}

This work was supported by a research grant - Hibah Penelitian Dasar, Ministry of Research, Technology and Higher Education, Republic of Indonesia (NKB 2617 / UN2.RST / HKP.05.00/2020).

\section{Acknowledgment}

The authors acknowledge financial support from research grant - Hibah Penelitian Dasar, Ministry of Research, Technology and Higher Education, Republic of Indonesia.

\section{References}

Argyle, M. (1957). Social pressure in public and private situations. The Journal of Abnormal and Social Psychology, 54(2), 172.

Baker, N. (2007). The fraud disconnect: a shared understanding of where fraud-related responsibilities lie can help internal auditing and management avoid costly short circuits. Internal Auditor, 64(2), 38-44.

Bartolucci, D. D., Bobek, T. M., \& LaTorre, J. A. (2011). Internal Audit: The Second Line of Defense. In Skalak, S. L, Golden, T.W, Clayton, M. M, \& Pill, J. S. (2nd Edition.), A Guide to Forensic Accounting Investigation (chapter 6).

Byrne, K. A., Silasi-Mansat, C. D., \& Worthy, D. A. (2015). Who chokes under pressure? The Big Five personality traits and decision-making under pressure. Personality And Individual Differences, 74, 22-28.

Coram, P., Ferguson, C., \& Moroney, R. (2008). Internal audit, alternative internal audit structures and the level of misappropriation of assets fraud. Accounting \& Finance, 48(4), 543-559.

Edwards, W. (1961). Behavioral decision theory. Annual Review of Psychology, 12(1), 473-498.

Evans III, J. H., Hannan, R. L., Krishnan, R., \& Moser, D. V. (2001). Honesty in managerial reporting. The Accounting Review, 76(4), 537-559.

Everett, J., \& Tremblay, M.S. (2014). Ethics and internal audit: moral will and moral skill in a heteronomous field", Critical Perspectives on Accounting, 25, 1-16.

Hunt, G. L. (2014). A descriptive comparison of two sources of occupational fraud data. Journal of Business \& Economics Research (JBER), 12(2), 171-176.

Khelil, I., Hussainey, K., \& Noubbigh, H. (2016). Audit committee-internal audit interaction and moral courage. Managerial Auditing Journal, 31(4/5), 403-433.

Leary, M. R. (1995). Self-presentation: Impression management and interpersonal behavior. Brown \& Benchmark Publishers.

Lord, A. T., \& DeZoort, F. T. (2001). The impact of commitment and moral reasoning on auditors' responses to social influence pressure. Accounting, Organizations and Society, 26(3), 215-235.

Markman, A. B., Maddox, W. T., \& Worthy, D. A. (2006). Choking and excelling under pressure. Psychological Science, 17, 944-948.

Natenzon, P. (2011). Essays in Behavioral Decision Theory. Princeton University.

Norman, C., Rose, A., \& Rose, J. (2010). Internal audit reporting lines, fraud risk decomposition, and assessments of fraud risk. Accounting, Organizations and Society, 35(5), 546-557.

Othman, R., Aris, N. A., Mardziyah, A., Zainan, N., \& Amin, N. M. (2015). Fraud Detection and Prevention Methods in the Malaysian Public Sector: Accountants' and Internal Auditors' Perceptions. Procedia Economics and Finance, 28, 59-67.

Rosdini, D., Sari, P. Y., Amrania, G. K. P., \& Yulianingsih, P. (2020). Decision making biased: How visual illusion, mood, and information presentation plays a role. Journal of Behavioral and Experimental Finance, 100347.

Sekerka, L. E., Bagozzi, R. P., \& Charnigo, R. (2009). Facing ethical challenges in the workplace: Conceptualizing and measuring professional moral courage. Journal of Business Ethics, 89(4), 565.

Slovic, P., Fischhoff, B., \& Lichtenstein, S. (1984). Behavioral decision theory perspectives on risk and safety. Acta Psychologica, 56(1-3), 183-203.

https://na.theiia.org/standards-guidance/Public\%20Documents/IPPFStandards- 2017.pdf

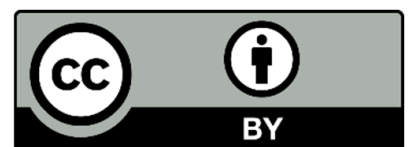

(C) 2021 by the authors; licensee Growing Science, Canada. This is an open access article distributed under the terms and conditions of the Creative Commons Attribution (CC-BY) license (http://creativecommons.org/licenses/by/4.0/). 